\title{
KAJIAN PERANGKAT PERLINDUNGAN DAMPAK RENDAH SUATU KAWASAN DI DALAM PERENCANAAN PENGEMBANGAN SUATU LAHAN DAN PELESTARIAN SUMBERDAYA AIR
}

\author{
Nikodemus Leomitro, Robby Yussac Tallar \\ Jurusan Teknik Sipil, Universitas Kristen Maranatha \\ Jalan Prof. drg. Soeria Sumantri, MPH, No. 65, Bandung, 40164 \\ e-mail: nikodemusleomitro@gmail.com,robbyyussac@yahoo.com
}

\begin{abstract}
ABSTRAK
Kajian ini bertujuan untuk menjabarkan suatu pendekatan yang berisi perangkat perlindungan suatu kawasan di dalam perencanaan pengembangan suatu lahan dan pelestarian sumberdaya air. Perangkat-perangkat tersebut adalah perencanaan tata guna lahan, perlindungan lahan yang bernilai hidrologis tinggi, pengawasan daerah penyangga badan air, pengontrolan erosi dan sedimen, manajemen air hujan, pengendalian debit diluar air hujan, dan program penatalayanan. Konsep dasar ini meliputi kajian detail yang terintegrasi dengan perangkat antara lain: hidrologi sebagai suatu bingkai kerja (framework) yang terpadu, menggunakan mikro manajemen, pengendalian banjir rencana (stormwater) pada sumbernya, penggunaan metode yang sederhana dan non-structural, dan membuat landscape multifungsional. Studi literatur ini mengambil Kawasan Depok sebagai contoh kasus. Kota Depok terletak di Provinsi Jawa Barat dan berada di bagian hulu DAS Citarum. Kajian ini juga menggunakan analisa SWOT untuk mendapatkan informasi-informasi yang berguna mengenai kondisi eksisting di studi area. Perangkat perlindungan ini ditawarkan untuk memudahkan para pemangku kebijakan dalam menyusun perencanaan detail. Kearifan lokal yang sesuai juga diperlukan untuk mendukung perangkat perlindungan suatu kawasan di dalam perencanaan pengembangan suatu lahan dan pelestarian sumberdaya air.
\end{abstract}

Kata kunci: pengembangan lahan, perangkat perlindungan dampak rendah, manajemen air.

\begin{abstract}
The main purpose of this literature study is to describe a watershed protection approach that applies several conservation devices for land development planning towards sustainable water resources development. These devices are as follows: land-use planning, high-value hydrological land conservation, aquatic buffers monitor, erosion and sediment control, stormwater best management practices, non-stormwater discharges and watershed stewardship programs. The basic concept includes detail study that is integrated with the device for example: hydrology as an integrated framework by using the micro-management, stormwater control plan at the source, simple method and non-structural, and creating a landscape multifunctional. The selected study area is Depok Area Depok Area as case study example. Depok Area is located on West java Province and upper Citarum Watershed. The study used SWOT analysis to get useful information about existing condition at study area. This conservation devices offered an easier approach for stakeholders in order to accomplish detail planning. Local wisdom is necessary to support conservation devices in certain area towards sustainable land development and water resources planning..
\end{abstract}

Keywords : land development, conservation tool, water management. 


\section{PENDAHULUAN}

Pengembangan lahan atau kawasan di suatu wilayah Daerah Aliran Sungai (DAS) adalah hal yang tidak dapat dihindari seiring dengan pertumbuhan penduduk yang demikian pesat. Timbulnya berbagai permasalahan yang terkait dengan pengembangan suatu kawasan berdampak pada kondisi sumberdaya air yang terdapat di dalam DAS tersebut. Beberapa permasalahan utama yang dihadapi dalam memanajemen sumber daya air adalah antara lain meliputi: kurangnya data mengenai potensi sumber air baku, ketidakseimbangan potensi dan kebutuhan air, konflik dalam pemanfaatan sumber air, kurangnya pelestarian sumber air, pengambilan air tanah secara berlebihan, turunnya kualitas sarana dan prasarana air minum, perubahan signifikan kualitas air baku dan belum tegasnya peraturan, kelembagaan, dan undang-undang sumber daya air. Maka dari itu diperlukan suatu pendekatan untuk melindungi atau setidaknya meminimalisasi dampak negatif seperti kerusakan-kerusakan yang dapat terjadi pada suatu kawasan di dalam wilayah DAS.

Kajian ini bertujuan untuk menjabarkan suatu pendekatan yang berisi perangkat perlindungan suatu kawasan di dalam perencanaan pengembangan suatu lahan dan pelestarian sumberdaya air. Penjelasan dengan beberapa teknik khusus dalam pengaplikasian dari perangkat perlindungan juga akan diberikan dalam kajian ini agar dapat masyarakat dapat berkontribusi langsung di dalam pengelolaan kawasannya masing-masing.

\section{PERANGKAT PERLINDUNGAN SUATU KAWASAN}

Pengaplikasian dari perlindungan dampak rendah suatu kawasan di dalam perencanaan pengembangan suatu lahan dan pelestarian sumberdaya air yang berada di dalamnya yaitu dengan menginventarisir perangkat-perangkat apa yang harus dikelompokkan dan bagaimana menerapkannya. Perangkat tersebut sedikitnya dikelompokkan menjadi 7 kelompok, yaitu:

\section{Perangkat 1: Perencanaan tata guna lahan}

Permasalahan utama dari perencanaan pengembangan suatu lahan yang telah ada adalah kesalahan atau ketidakcermatan dalam perencanaan tata guna lahan terutama dalam hal pengaturan jumlah dan lokasi-lokasi penempatan yang sudah disesuaikan dengan kondisi

keairan yang tersedia. Pemangku kebijakan dan/atau pengembang harus berpikir dan menganalisa terlebih dahulu sebelum melaksanakan pengembangan suatu lahan. Beberapa sumberdaya air yang tersedia di lahan tersebut harus dijaga kelestariannya 
seiring dengan tata guna lahan yang direncanakan dan akan dikembangkan di lahan tersebut. Analisa perhitungan akibat dampak perubahan dan pengembangan tata guna lahan ini dapat menggunakan metode Rasional sehingga diperhitungkan nilai koefisien air larian (surface runoff) yang menentukan luaran debit akibat perencanaan atau perubahan tata guna lahan tersebut.

\section{Perangkat 2: Konservasi lahan yang bernilai hidrologis tinggi}

Kalau pada perangkat 1 lebih menekankan pada seberapa lahan kedap air yang dapat dikurangi di dalam suatu lahan sehingga debit luaran dapat ditekan sebanyak mungkin, maka dalam perangkat berikutnya adalah terkait konservasi lahan. Usaha lain yang dapat dilakukan adalah mengkonservasi lahan yang masih alamiah dan bernilai hidrologis tinggi. Lahan bernilai hidrologis tinggi adalah lahan yang tersusun lengkap sehingga dapat menjalankan proses siklus hidrologi secara maksimal di dalamnya.

\section{Perangkat 3: Pengawasan daerah penyangga badan air}

Daerah penyangga badan air adalah daerah yang berada disekitar badan air dan berpengaruh langsung pada kondisi badan air. Daerah penyangga badan air ini rentan mengalami kerusakan karena minimnya maupun aturan akan pengelolaan dari daerah tersebut. Maka dari itu diperlukan pengawasan terhadap daerah penyangga badan air.

\section{Perangkat 4: Pengontrolan erosi dan sedimen}

Erosi dan sedimen yang terjadi di wilayah yang akan dikembangkan harus dikontrol agar dapat meminimalisir potensial erosi. Jenis tanah dan kemiringan lahan adalah contoh dari variabel yang mempengaruhi perencanaan pengontrolan erosi dan sedimen.

\section{Perangkat 5: Manajemen air hujan}

Manajemen air hujan dalam suatu kawasan adalah hal yang mutlak harus dipikirkan dan dilakukan oleh pengembang lahan. Perencanaan pengembangan suatu lahan harus memasukkan perencanaan pengelolaan air hujan yang dapat dipanen (rainwater harvesting) sehingga dapat digunakan kembali maupun pengelolaan hujan badai (stormwater) yang bisa berakibat banjir.

\section{Perangkat 6: Pengendalian debit diluar air hujan}

Debit diluar air hujan adalah debit yang berasal dari sumberdaya air yang ada maupun oleh aktivitas manusia yang berupa limbah cair. Dalam banyak kasus, limbah cair yang 
dihasilkan oleh aktivitas manusia berkontribusi cukup besar dalam mencemari badan air. Bagian dari pengendalian debit diluar air hujan antara lain tanki septik dan saluran sanitasi. Limbah cair yang dikendalikan ini terdiri dari jenis air hitam (blackwater) dan air abu-abu (greywater).

\section{Perangkat 7: Program penatalayanan}

Program penatalayanan terkait dengan keberlanjutan dari konservasi dengan memonitoring pelaksanaannya. Tujuan dari perangkat ini adalah untuk meningkatkan partisipasi masyarakat di dalam perhatian dan keterlibatannya untuk mengelola lahan yang sudah dikembangkan. Program-program ini meliputi pendidikan dan pelatihan, perawatan dan pemeliharaan dari fasilitas-fasilitas yang terkait yang sudah dibangun.

\section{CONTOH STUDI KASUS}

Studi literatur ini mengambil Kawasan Depok sebagai contoh kasus. Kota Depok terletak di Provinsi Jawa Barat dan berada di bagian hulu DAS Citarum. Kota Depok merupakan wilayah penyangga Ibukota Jakarta dan termasuk wilayah terpadu JABODETABEK (Jakarta-Bogor-Depok-Tangerang-Bekasi). Kawasan Depok merupakan kawasan andalan untuk daerah resapan air dengan arahan pemanfaatan ruang sebagai kawasan perkotaan, budidaya lahan basah dan lahan kering. Untuk itu, dalam rangka mewujudkan tata ruang terpadu di Kawasan Depok, dilakukan identifikasi awal terlebih dahulu tentang potensi-potensi yang ada terutama potensi sumberdaya air.

\subsection{Kilasan Karakteristik Fisik Kawasan Depok}

Kawasan Depok beriklim tropis dengan curah hujan rata-rata sekitar $327 \mathrm{~mm}$. Secara umum, topografi Kawasan Depok terbagi menjadi 3 bagian yaitu wilayah dengan kemiringan lereng antara 2-8\% (datar) tersebar di bagian utara meliputi Kecamatan Limo, Kecamatan Beji dan Kecamatan Cimanggis. Wilayah dengan kemiringan lereng antara 8$15 \%$ tersebar hampir di seluruh dan wilayah dengan kemiringan lereng $>15 \%$ terdapat di wilayah sepanjang Sungai Ciliwung, Cikeas dan bagian selatan Sungai Angke. Dari segi hidrogeologi didominasi oleh kelompok litologi endapan lanau, pasir, kerikil dan kerakal hasil endapan batuan vulkanik dengan kondisi akuifer tergolong tinggi dengan debit antara 1-5 liter/det. 


\subsection{Kilasan Potensi Sumberdaya Air}

\subsubsection{Sistem Air Bersih dan Kotor}

Sistem air bersih di Kawasan Depok menggunakan sumber air baku dari Sungai Ciliwung, Sungai Angke, Sungai Pesanggrahan, Mata Air Ciburial dan air tanah dalam yang pengelolaannya dilakukan oleh PDAM Kawasan Bogor. Sistem air kotor atau air limbah dilayani dengan sistem perpipaan (off-site) dan sistem setempat (on-site). Sistem perpipaan masih dalam pengembangan dan hanya dilaksanakan di kelurahan Beji sebagai proyek percontohan (pilot project). Sementara sistem setempat secara umum menggunakan septic-tank.

\subsubsection{Sungai dan Situ}

Kawasan Depoknya memiliki setidaknya 10 sungai yang melintasi wilayahnya antara lain Sungai Ciliwung, Sungai Angke, Sungai Pesanggrahan, Sungai Krukut, Sungai Grogol, Sungai Sugutamu, Sungai Sunter, Sungai Cipinang, Sungai Cijantung, dan Sungai Cikeas. Sungai Ciliwung merupakan sungai utama yang menjadi kendala terbesar bagi pengembangan Kawasan Depok. Untuk situ/danau sendiri, setidaknya 19 situ/danau baik alamiah maupun buatan berada di wilayah Kawasan Depok antara lain: Situ Bojong Sari, Situ Universitas Indonesia (UI), Situ Citayam, Situ rawa Besar, Situ Pladen, Situ Bahar, Situ Rawa kalong dan lainnya. Beberapa situ mengalami perubahan fungsi dan semakin meyempit luasannya. Permasalahan sedimentasi, sampah dan kondisi kualitas air sungai yang semakin memburuk adalah bagian dari permasalahan yang ada di wilayah sungai.

\subsection{Kilasan Potensi lainnya}

\subsubsection{Kawasan Hijau}

Kawasan hijau di kawasan Depok salah satunya adalah kawasan taman hutan raya Pancoran Mas. Kawasan ini memiliki luas sekitar 6 hektar yang dahulunya merupakan cagar alam yang dilindungi, tetapi sejak tahun 1999 dikeluarkan Keputusan Menteri kehutanan dan Perkebunan No. 278/KPTS-II/1999 tentang perubahan fungsi cagar alam menjadi taman hutan raya yang dikembangkan $10 \%$ dari luasannya menjadi wisata alam. Kawasan hijau lainnya berada di Kecamatan Cimanggis dan bernama Kawasan Hijau Pemancar PPI yang memiliki luas sebesar kira-kira 187 hektar, Kawasan Studio Alam TVRI di Kecamatan Sukmajaya dengan luas sebesar kira-kira 32 hektar, dan Kawasan Hutan Kota Universitas Indonesia di Kecamatan Beji seluas 75 hektar.

Kajian Perangkat Perlindungan Dampak Rendah Suatu Kawasan di Dalam Perencanaan 


\subsubsection{Flora dan Fauna}

Beberapa flora dan fauna yang berada di Kawasan Depok dilindungi oleh beberapa undang-undang demi menjamin keberlangsungannya, antara lain: Keputusan Menteri Dalam Negeri No.522.5/1958/SJ tanggal 2 Juni 1990 tentang penetapan flora dan fauna daerah, surat Direktur Jenderal Pembangunan Daerah No. 660.1/2585/Bangda tanggal 25 Nopember 1998 tentang Identitas Flora dan Fauna Tingkat II seluruh Indonesia. Disamping itu juga dari Walikota Depok mengeluarkan keputusan no.660.1/30/Kpts/huk/2000 tentang penetapan flora dan fauna identitas daerah Kawasan Depok yaitu Manggis Depok (Garcinia mangostana kultivar Depok) dan burung jalak kerbau (Archidotheres javanicus).

\section{DISKUSI}

Kawasan lindung dan kawasan resapan air adalah kawasan yang ditetapkan untuk diterapkan di Wilayah Depok. Untuk itu pembangunan di kawasan ini harus memberikan perlindungan dengan memperhatikan konservasi air tanah melalui kepadatan bangunan, vegetasi dan beberapa teknologi dampak rendah seperti sumur resapan seperti pada Gambar 1. Penerapan konsep pembangunan yang ramah lingkungan diharapkan menggunakan analisa hidrologi secara detail untuk menganalisa kondisi sebelum pengembangan / pra pengembangan dan sesudah pengembangan pada suatu kawasan. Konsep dasar pembangunan kawasan ini meliputi kajian detail yang terintegrasi dengan perangkat antara lain: hidrologi sebagai suatu bingkai kerja (framework) yang terpadu, menggunakan mikro manajemen, pengendalian banjir rencana (stormwater) pada sumbernya, penggunaan metode yang sederhana dan non-struktural, dan membuat landscape multifungsional seperti pada Gambar 2.

Pengaturan tata-guna lahan yang sesuai untuk terciptanya keseimbangan lingkungan termasuk di dalamnya agar kualitas air dapat terus terjaga sesuai dengan peruntukkannya. Mengembalikan fungsi hutan dan daerah resapan air agar dapat dipelihara, dikelola sebaik mungkin. 


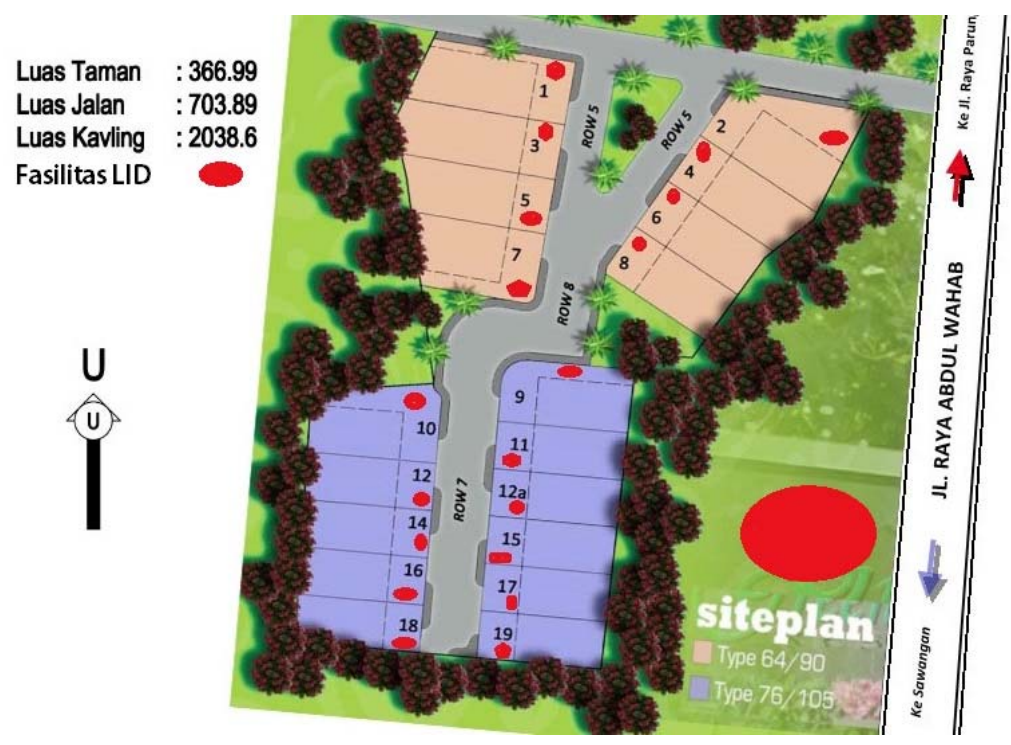

Gambar 1. Contoh perencanaan wilayah di Kawasan Depok dengan perangkat perlindungan dampak rendah.

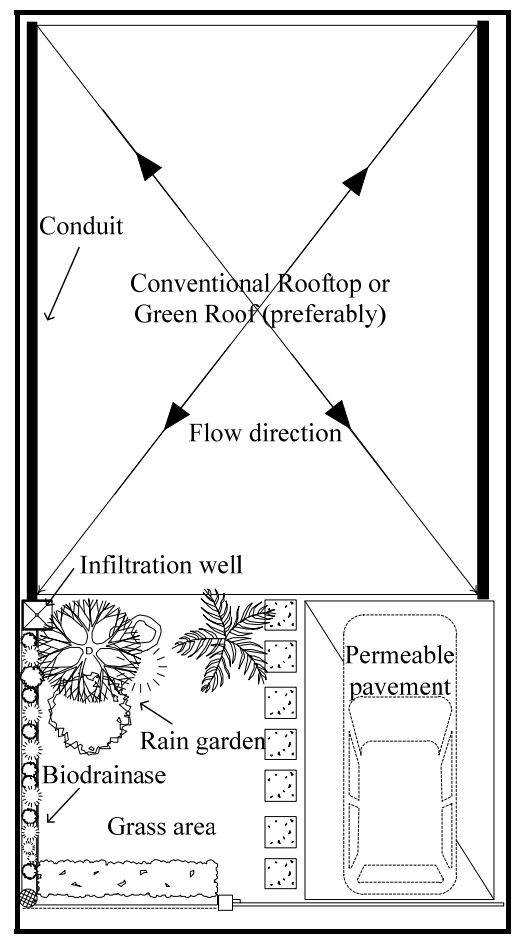

Gambar 2. Tipikal desain dari adaptasi teknologi dampak rendah (LID) untuk perumahan sederhana (gambar tidak berskala)

Terkait dengan studi kasus di kawasan Depok, beberapa perangkat sudah diterapkan oleh pihak pemangku kebijakan (stakeholders) seperti perencanaan tata guna 
lahan untuk beberapa kawasan lindung, pengawasan badan air seperti danau/situ tertentu dan sebagainya. Analisa lengkap SWOT lebih lengkap dapat dilihat pada Tabel 1. .

Tabel 1. Tabel Analisa SWOT di Kawasan Depok

\begin{tabular}{|c|c|}
\hline Komponen & Deskripsi \\
\hline Kekuatan/Potensi & $\begin{array}{l}\text { - Beberapa area terbuka dan area basah seperti danau- } \\
\text { danau buatan dipersiapkan untuk menahan sekaligus } \\
\text { menampung air hujan. } \\
\text { - Menurunnya kualitas air permukaan di badan air } \\
\text { telah menjadi perhatian dari pemerintah dan } \\
\text { masyarakat. }\end{array}$ \\
\hline Kelemahan & $\begin{array}{l}\text { - Kurangnya informasi data kualitas dan kuantitas } \\
\text { sumberdaya air yang konsisten dan terunut } \\
\text { berdasarkan kurun waktu. } \\
\text { - Tumpang tindihnya fungsi atau peruntukan } \\
\text { sumberdaya air terutama sungai dan danau sehingga } \\
\text { tidak fokus dalam peengelolaan dan } \\
\text { pengembangannya. } \\
\text { - Tidak adanya konsep terpadu (blue print) } \\
\text { sumberdaya air terutama dalam memenejemen dan } \\
\text { melestarikannya. }\end{array}$ \\
\hline Peluang & $\begin{array}{l}\text { - Masih banyak sumberdaya air di Kawasan Depok } \\
\text { yang bersifat alamiah dan belum diarahkan ke } \\
\text { konsep pengembangan dampak rendah.. } \\
\text { - Potensi sumberdaya air yang berlimpah dan masih } \\
\text { dapat dikembangkan. }\end{array}$ \\
\hline Ancaman/Tantangan & $\begin{array}{l}\text { - Beberapa parameter kualitas air di badan air } \\
\text { Kawasan Depok telah melebihi ambang batas seperti } \\
\text { fecal coliform dan total coliform. } \\
\text { - Efluen dari aktivitas manusia semakin meningkat } \\
\text { seiring dengan kepadatan penduduk yang meningkat } \\
\text { pula. } \\
\text { - Program pengawasan (monitoring) yang masih } \\
\text { sangat tergantung dengan kebijakan pemangku } \\
\text { kebijakan yang terkait dengan masalah keuangan. } \\
\text { - Masalah wewewang antar biro pemerintahan yang } \\
\text { terkait masih tumpang tindih satu sama lain. }\end{array}$ \\
\hline
\end{tabular}

Pengaturan pembuangan limbah yang diijinkan baik dari sektor industri yang terutama, maupun domestik. Diharapkan semua sektor memiliki sistem pengolahan 
limbah yang baik secara individu maupun komunal sehingga tidak langsung dibuang ke badan air. Kalaupun langsung dibuang ke badan air, diharapkan dapat memenuhi kualitas air yang diijinkan, sehingga badan air mampu melakukan "self-purification" seperti yang diharapkan.

\section{SIMPULAN}

Penerapan secara menyeluruh dari ketujuh perangkat ini memerlukan keterpaduan dalam perencanaan pengembangan yang ditinjau dari berbagai teknis, sosial, ekonomi, lingkungan dan budaya masyarakat yang tinggal di dalam suatu kawasan. Perangkat ini ditawarkan untuk memudahkan para pemangku kebijakan dalam menyusun perencanaan detail. Perangkat perlindungan dampak rendah pada suatu kawasan ini sangat diperlukan dalam perencanaan pengembangan suatu lahan. Banyak aspek-aspek diluar aspek teknis yang akan terkait dan perlu diperhatikan. Salah satunya adalah permasalahan pembagian pendapatan daerah secara adil, sehingga tiap-tiap daerah yang dilewati oleh badan air tidak saling berlomba untuk membuka lahan demi meningkatnya pendapatan daerahnya masing-masing.

Wilayah yang memiliki tata-guna lahan seperti sektor industri, jasa maupun pemukiman, harus membagi pendapatan yang diperoleh dari pajaknya ke wilayah atau daerah yang banyak memiliki tata-guna lahan hutan, daerah resapan air dan lainnya yang tidak dapat dipungut pajak. Pembagian itu sebagai kompensasi agar tata-guna lahan yang berfungsi untuk memelihara cadangan air maupun kualitas air dapat terjaga dan terus terpelihara. Pemanfaatan data karakteristik suatu DAS dapat juga digunakan untuk memitigasi bencana seperti banjir dan tanah longsor. Disamping itu, penentuan besarnya sanksi yang harus ditanggung bagi yang melanggar harus dipikirkan seksama dan disepakati oleh semua pihak agar adil misalkan untuk sektor industri apakah itu ditutup, dipindahkan atau diberi denda yang tujuannya agar dapat menjaga kualitas air. Begitu juga dengan pemukiman yang melanggar KGB, tidak mempunyai IMB atau yang tidak mempunyai sertifikat hak milik, harus ditindak secara tegas, terlebih yang berada di sekitar wilayah badan air.

\section{SARAN}

Perlunya dilakukan penelitian lebih lanjut mengenai detail penerapannya dalam skala mikro sehingga didapat gambaran yang jelas secara menyeluruh di dalam menerapkan perangkat perlindungan dampak rendah suatu kawasan. Penerapan teknologi yang berkembang akhir-akhir ini juga dapat membantu proses pemetaan dalam 
pengembangan suatu kawasan seperti GIS (Geographical Information System) untuk melakukan analisa terhadap informasi-informasi spasial dan pendukungnya untuk menghasilkan informasi baru yang diperlukan. Kearifan lokal yang sesuai juga diperlukan untuk mendukung perangkat perlindungan suatu kawasan di dalam perencanaan pengembangan suatu lahan dan pelestarian sumberdaya air.

\section{DAFTAR PUSTAKA}

1. Anonim. (2000). Program Pengelolaan Kawasan Lindung Kota Depok. Sekretariat Daerah Kota Depok bagian Lingkungan Hidup.

2. EPA Victoria. (2006). Keeping our stormwater clean - a builder's guide. Melbourne Water, Victorian Government, EPA Victoria. www.melbournewater.com.au

3. Housing Industry Association. (2005). Site management guide for residential builders. [additional reading now found on www.catchmentsandcreeks.com.au]

4. International Erosion Control Association. (2008). Best practice erosion and sediment control. www.austieca.com.au

5. Macgregor, CJ. (2008). Guidelines for erosion and sediment control at building sites in the South West of WA. Centre of Excellence in Natural Resource Management, University of Western Australia and the South West Catchments Council. [additional reading now found on www.subiaco.wa.gov.au]

6. NSW Department of Environment and Conservation. (2006). A resource guide for local councils: erosion and sediment control. www.environment.nsw.gov.au

7. Stormwater Trust. (2008). Managing urban stormwater - soils and construction, Volume 2A Installation of services. NSW Department of Environment and Climate Change www.environment.nsw.gov.au

8. Witheridge, G. (2003). Erosion and sediment control. Environment design guide, DES 52. Australian Institute of Architects, Melbourne. www.environmentdesignguide.com.au

9. Witheridge, G. (2010). Erosion and sediment control - a field guide for construction site managers. Catchments \& Creeks Pty Ltd. $\underline{\text { www.catchmentsandcreeks.com.au }}$ 